\title{
Medellín, la ciudad de la ladera en disputa con la imaginada*
}

\author{
Luz Dary Ruiz Botero \\ Hugo Alexander Villa Becerra \\ Diego Mauricio Montoya Bedoya
}

Grupo de Investigación y Estudios en Desarrollo Local y Gestión Territorial. Institución Universitaria Colegio Mayor de Antioquia, Colombia.

Recibido: 30 de junio del 2017 / Aprobado: 10 de setiembre del 2017

doi: 10.26439/limaq2018.n004.2255

El texto describe el proceso de configuración sociohistórica de Medellín como parte de una tensión entre dos lógicas de producir y reproducir la ciudad. En dicho escenario los asentamientos informales adquieren formas de construcción social del territorio y, por tanto, integran otras maneras de poblamiento. Se evidencia los diferentes momentos históricos de tensión entre ciudad real e imaginada ante la intención de los pobladores urbanopopulares de domar la ladera; asimismo, la relación de estos con los Gobiernos locales frente a sus intervenciones.

construcción social del territorio, ciudad imaginada y ciudad real, asentamientos informales, intervenciones urbanas

Medellin, the city on the slope in dispute with the imagined city

The text describes the socio-historical configuration process of Medellin as part of the tension between two logics of producing and reproducing the city. In such scenario, informal settlements have shaped the social construction of the territory, thus integrating "other" ways of settlement. To that end, this research shows different historical tension moments between real and imagined city, the intention of urban-popular settlers to "tame the hillside", and their relationship with local governments in front of such interventions.

social construction of the territory, imagined city and real city, informal settlements, urban interventions

* Este texto es resultado de la investigación Diagnóstico social participativo del barrio El Pacífico de la comuna 8 de Medellín, en el marco de los procesos de gestión comunitaria del desarrollo local y territorial 2015-2017. Se llevó a cabo gracias a la alianza entre el Grupo de Investigación en Desarrollo Local y Gestión Territorial de la Institución Universitaria Colegio Mayor de Antioquia, la Mesa de Vivienda y Servicios Públicos de la comuna 8, y la Junta de Acción Comunal de El Pacífico. Estudio inspirado en la investigación acción participativa (IAP). 


\section{TENSIÓN ENTRE LA CIUDAD IMAGINADA Y LA CIUDAD REAL}

En Medellín se puede evidenciar lo indicado por Romero (1976) para la configuración de las ciudades latinoamericanas: la ciudad de la fundación o imaginada por los españoles en la colonia, así como también la ciudad real que poco a poco fue tomando conciencia de su lugar en la región y en la historia. La primera, como la ciudad del acta, el escribano, la espada y la cruz; el remedo de ciudades españolas que asumen hasta sus nombres, en tanto son fundadas y mantenidas para asegurar la homogeneidad y la dependencia del mundo colonial para crear una América hispánica, europea, católica y sin expresión propia. Más que ciudades físicas se apostó por crear sociedades compactas y homogéneas, con pretensiones de moldear la realidad. Para ello, disponían de un rígido sistema político y jurídico que se basaba en la estructura ideológica de la monarquía cristiana de carácter jerárquico. Ciudades cuyas funciones implican el control territorial, la reproducción cultural y racial, así como el aporte al desarrollo económico según las necesidades del sistema mundial. La segunda, la ciudad real, pequeña, de pocos vecinos inicialmente y de muchos riesgos e incertidumbres. La ciudad que descubre que está en una región próspera, tiene historia y futuro propio. La de quienes llegan a ella a levantar su propia casa o a instalarse en una ajena, los que viven de su trabajo en la ciudad."Y tomó conciencia, finalmente, de que había empezado a tener una historia de la que no podía prescindir, cuyo peso se hacía presente en cada situación real y en cada momento en que era necesario tomar una decisión" (Romero, 1976, p. 16).

Sin embargo, en Medellín se encuentra irresuelta esta tensión entre la ciudad real y la imaginada, ante la insistencia de ciudades que siguen atadas a las imposiciones de la metrópoli, hoy enunciada como la sociedad global, y que, pese a la persistencia de sus realidades históricas, la niegan y la tratan de borrar con las líneas de sus trazados y obras urbanas. No hay un paso de la ciudad imaginada a la real, ni es claro el acto de conciencia; en cambio, se mantiene una tensión confusa entre la coexistencia de ambas, y de ello se hará exposición en adelante. Ambas lógicas de ciudad se encuentran en el territorio y se disputan las formas de ordenar el espacio urbano, a veces en confrontación entre sus actores; en otras, se imbrican. La Medellín imaginada se sustenta desde la planeación oficial de la ciudad a partir de legislaciones y orientaciones de la administración municipal para ordenar el territorio y 
disponer la vida urbana, en especial en las zonas estratégicas y marginales de la ciudad, y en la contención del perímetro urbano. La ciudad real se evidencia en las maneras como los nuevos pobladores sobreviven en las zonas de ladera, disputándose un territorio y en ser parte de Medellín aun al margen de la planeación oficial. En consecuencia, es paradójica su lucha en contra de esas legislaciones, así como por ser incluidos en ellas.

De esa manera, la ciudad imaginada, la de la eterna primavera, la que muda de piel y la reconocida internacionalmente por la innovación ${ }^{1}$ en sus intervenciones urbanas entra en tensión con la otra ciudad, la de las exclusiones, múltiples violencias, la de la ladera que se autoconstruye desde los pobladores. Como nos recuerda Nieto (2008), Medellín comenzó a evidenciar...

dos procesos de configuración marcadamente opuestos y desiguales. De un lado, una ciudad próspera y pujante con grandes avances tecnológicos e industriales, y de otro lado, una ciudad que se construía desde las laderas, desde los márgenes y la periferia, por nuevos pobladores sumidos en altos niveles de desigualdad y exclusión espacial, social y económica. (p. 118)

Un factor relevante en la conformación de las ciudades lo da el crecimiento poblacional por la movilidad, que al parecer coincide con los flujos migratorios en el continente americano: "Se migraba para sobrevivir, encontrar un futuro, evadir persecuciones políticas, raciales y religiosas" (Carballeda, 2012,p.3).En el caso de Colombia, la movilidad a las ciudades de poblaciones mayoritariamente rurales se da para sobrevivir a la vulnerabilidad en el campo, asociada a los bajos índices en satisfacción de necesidades básicas y la violencia social y política; visualizar una posibilidad de desarrollo y mejor futuro desde la educación y el empleo para la familia, y para evadir las persecuciones vinculadas a las disputas políticas entre partidos y grupos armados.

1 Por sus avances en cuanto a sistemas de transporte masivo, tales como el metro, Metrocables, tranvía, Metroplús; por sus desarrollos urbanos en megaproyectos como Parques del Río, Jardín Circunvalar, parques lineales, bibliotecas, jardines infantiles y escuelas públicas en algunas de las comunas de la ciudad, entre otras obras de infraestructura, le han dado el reconocimiento de la Ciudad más Innovadora del Mundo en el 2013 y premio mundial de transformación urbana Lee Kuan Yew World City Prize en el 2016. 
En Colombia, por ejemplo, esta migración indica que, en 1938, el 70,9 \% de la población era rural; en 1951, 61,1\%; mientras que en 1964 era de $47 \%$ (DANE, como se citó en Giraldo, 2015, p. 11). Sin embargo, el Programa de las Naciones Unidas para el Desarrollo (PNUD), en su Informe sobre desarrollo humano del 2011, aclaró que si bien para el 2015 el 75 \% de la población vivía en zonas urbanas, el $25 \%$ que habitaba en las zonas rurales ocupaba cerca del 94,4 \% del territorio nacional, por lo cual el país mantenía un predominio rural en la ocupación del suelo (PNUD, 2011,p. 18). Esta proporción se mantiene en ciudades como Medellín, donde el 71,8 \% del territorio corresponde a la zona rural desde sus cinco corregimientos. De los 2441123 habitantes, en el 2014, el $93 \%$ se concentró en la zona urbana, cuyo patrón de crecimiento acelerado se corresponde con la configuración sociohistórica bastante compleja donde convergen las tensiones entre dos modos de hacer ciudad que se mantienen desde su fundación, lo cual se presenta a continuación desde tres momentos significativos en las maneras de hacer ciudad domando la ladera y resaltando el origen campesino de muchos de los nuevos pobladores.

\section{EXPRESIONES EN EL TIEMPO DE LOS MODOS DE DOMAR LA LADERA}

La anterior situación se expresa desde que la ciudad fuera erigida como Villa en 1675: enfrentó la tensión con la ciudad real de las 60 familias asentadas para el momento y la ciudad definida por las normas (Melo, 1997), lo cual será una constante en su historia. Medellín se gestó al asumir la estructura de ciudad colonial, que impuso la retícula de las cuadras alrededor de las plazas desconociendo y transformando sus antecedentes de poblamiento e incluso sus condicionantes geográficos:

Una especie de contradicción mental permanente: la obsesión por tener vías rectas y amplias, como criterio esencial del urbanismo, pero que estuvo casi siempre detrás de los hechos: las casas que se iban haciendo en los nuevos barrios seguían en alguna medida las curvaturas impuestas por el medio, por las quebradas y por las curvas del nivel, sobre todo cuando comenzó a extenderse la ciudad más allá del núcleo relativamente plano que ocupó hasta 1880 . Después llegaba el esfuerzo municipal de ampliar y rectificar, derribando lo construido, y tratando de eliminar los rasgos de la topografia: cubrir quebradas, 
hacer manzanas estrictamente cuadradas, rectificar las quebradas y los ríos. Los dirigentes de Medellín fueron siempre, como en el poema del Tuerto López, amantes de la línea recta. (Melo, 1997)

Conforme a los intereses de la dirigencia en Medellín en cuanto a la infraestructura como indicador de modernidad y progreso, la apuesta urbana y el desarrollo arquitectónico hasta 1870 se centraron en las conexiones viales, el mejoramiento de la ciudad, el auge de renovación y expansión urbana. Esto posibilitó que, para mediados del siglo XVIII e inicios del XIX, Medellín tuviera un sólido crecimiento y se consolidara como el primer centro urbano de Antioquia, en gran medida estimulado por el crecimiento económico derivado de las actividades comercial, bancaria e industrial entre 1870 y 1932, que la ubicaron tempranamente como la segunda ciudad colombiana. Así, en poco tiempo...

pasó de la aldea de laVilla de la Candelaria a verse y sentirse ciudad de Medellín; su estructura urbana fue modificada con el fin de parecerse al imaginario que se estaba construyendo y que se quería proyectar hacia fuera; y la arquitectura respondió a variados intereses, dejó atrás la poquedad y austeridad de muchos decenios para construirse y constituirse en parte de la nueva imagen y realidad urbana. (González, 2007, p. 12)

De otra parte, domar la ladera es la expresión de los nuevos pobladores de Medellín que llegan a habitar la ciudad y se enfrentan por esa migración forzada a ocupar las partes altas del valle, la ladera, también denominada periferia. Domarla implica, inicialmente, disputarse con la naturaleza la construcción de sus viviendas en zonas empinadas y en riesgo de deslizamientos; organizarse entre vecinos para conseguir el acceso al agua y la electricidad, y construir espacios comunes; enfrentarse a la institucionalidad representada en la fuerza pública —en las más de las veces - para ocupar tierras invadiéndolas, y luego para ser reconocidos como parte de la ciudad y acceder a los recursos públicos. La utilizan también para indicar cómo la institucionalidad pública de la ciudad pretende contener la expansión urbana desde diversas intervenciones fisicas, a través de la regulación y el direccionamiento de los usos del espacio urbano mediante legislaciones y planes de ordenamiento territorial. 
En la Medellín de las zonas de ladera se pueden evidenciar las tensiones entre las maneras de producir y reproducir la ciudad. Se identifican en su configuración como ciudad real unos tránsitos en el tiempo, según el proceso de poblamiento y la construcción social del territorio, y también en los lineamientos de los gobiernos locales para ordenar y contener la expansión urbana conforme a esa Medellín imaginada y proyectada por la institucionalidad público-estatal.

1. De campesino a obrero (1920-1940). La vida en la ciudad fue promovida por la expectativa del progreso puesta en la ilusión de mejores ingresos económicos para la familia con el trabajo en las fábricas de textiles de Medellín; el ascenso social por el estatus otorgado al ser obrero en relación con el campesino y, finalmente, por las posibilidades de educación para los hijos como promesa de mejor futuro para la descendencia. Estos imaginarios se vieron estimulados por el desarrollo de proyectos de construcción de barrios obreros y fueron acompañados de la reivindicación de condiciones de vida desde los discursos y las acciones de los sindicatos, que propiciaron la formación política de los obreros al incrementar su pertenencia al espacio urbano, la constitución de una identidad en las dinámicas que implica la nueva vida en la ciudad y para afrontar las tensiones propias de este entorno.

Por las transformaciones urbanas vividas en este periodo como efecto del crecimiento industrial, se le denominó ciudad del ensanche (18901937) (Perfetti, 1996, p. 96), en tanto fue producto de la adopción de los lineamientos del plano Medellín Futuro en 1913 con el urbanismo de ciudad posliberal europea. Esto implicó ampliar las áreas urbanizadas, la intervención en el centro antiguo de la ciudad, el ensanche urbano, la expansión vial y de las áreas verdes, la modernización y la ampliación del agua y los desagües, así como la diversificación del transporte público. Para el siglo xx, Medellín se caracterizó por el crecimiento demográfico, generado por el desarrollo industrial, los procesos de urbanización y expansión urbana, y la diferenciación social y espacial de sus pobladores, precisados en el Plano Urbano y el Plan Regulador, que se preocupan por la ciudad moderna, lo cual implica cierto manejo del espacio urbano. 
El plano urbano de 1912 nos muestra la dirección en la que debe crecer la ciudad: los sectores ricos se mueven hacia el norte, los sectores populares ocupan los lugares más altos hacia el occidente... y hacia el sur... y en la parte alta de la ladera oriental... y en las nuevas partes del llano del norte hacia el río. (Melo, 1997, p. 2)

En este periodo primó la formalidad en el acceso a la tierra y la construcción de viviendas conforme a los lineamientos de las entidades responsables. Sin duda, la migración económica y la vinculación a las fábricas propiciaron el acceso económico a las familias y las condiciones favorables para habitar la ciudad en barrios céntricos, cercanos a las industrias y con dotación de equipamientos importantes. Además, la formación de sindicatos obreros y el acceso a la educación superior de algunos integrantes de la familia favorecieron la instauración de otro estatus social en la ciudad, más cercano a la clase media.

El poblamiento de las zonas de ladera aún no era tan relevante en la ciudad para la época, y la concentración de la población se llevaba a cabo sobre todo cerca de los establecimientos comerciales y las fábricas en el centro de Medellín, asunto que empezó a cambiar en el siguiente periodo, así como los motivos prioritarios de la migración a la ciudad.

2. De campesino a desarraigado (1945-1980). Si el anterior periodo fue marcado por el crecimiento de la ciudad formal en correspondencia con el auge económico y la intervención urbana para la población obrera, este estuvo fuertemente influenciado por un agudo crecimiento poblacional de la ciudad como efecto de las confrontaciones sociopolíticas del país. Miles de campesinos colombianos buscaron sobrevivir a las múltiples situaciones de violencia, por lo cual llegaron a las ciudades y reconfiguraron la ocupación urbana en el país.

Mientras el desplazamiento forzado para 1945 se generó por el conocido periodo de la Violencia en Colombia con el enfrentamiento entre el partido Liberal y el Conservador, para 1980 obedecería a la confrontación entre actores del conflicto armado colombiano: guerrillas, paramilitares y fuerza pública. Los campesinos se vieron obligados a abandonar sus tierras y enseres para salvar su vida y las de sus familiares; en consecuencia, migraron a ciudades intermedias o principales del país. 
Estas confrontaciones generaron, entre otras consecuencias, asesinatos, amenazas, desapariciones forzadas y desplazamientos ${ }^{2}$, que despojaron de los territorios a miles de familias campesinas y las forzaron a "aterrizar" en las ciudades, con la expectativa de hacerse de un lugar para continuar la vida, siendo las periferias y las zonas de ladera los territorios desde donde se disputaron su derecho a la ciudad, con lo que se configura así la otra ciudad.

Entre 1958 y 1972, llegaron a 600.000 los habitantes residentes en núcleos piratas de la ciudad (el 50\% de la población). La magnitud de este fenómeno dio lugar a la formación de una ciudad ilegal, construida por fuera del perímetro urbano, al margen de las escasas normas de construcción existentes y con mecanismos informales de articulación a la vida económica de la urbe: las laderas que antes rodeaban la ciudad empezaron a ser ocupadas, creando así cambios profundos en la espacialidad y en la dinámica social de la ciudad. (Primed, 1996, pp. 9-30)

De esa manera, los nuevos pobladores urbanos pusieron en evidencia los conflictos por los que atraviesa el país, al tiempo que las ciudades dejaban de ser el espacio de unos privilegiados para convertirse en objeto de disputa. Ante la imposibilidad de quedarse en la ciudad, fue la llegada masiva a esa montaña la oportunidad de volver a empezar rehaciendo sus vínculos y desplegando los saberes propios de la vida en el campo.

Una zona que no hace parte de la ciudad [...] para nosotros es muy importante ya que fue el único lugar que nos acogió después de la guerra, que nos envió acá, que nos sacó de nuestros hogares y nos llevó a un lugar desconocido... ese pequeño pedacito de monte que nos acogió,

2 Entre 1985 y 2013, de acuerdo con las estimaciones de Codhes -Consultoría para los Derechos Humanos y el Desplazamiento-, 5921924 personas se han visto en la necesidad de desplazarse para proteger su vida e integridad y las de sus familias. Esto significa, de acuerdo con las estimaciones mundiales de Internal Displacement Monitoring Centre, que Colombia es el segundo país en el mundo con mayor número de desplazados internos. (Codhes, Reporte general, 2013). Las ciudades son los principales lugares de destino de las personas desterradas, y Medellín es la segunda ciudad receptora de este tipo de población en Colombia (Gómez, 2010, p. 10). 
con mucho amor fuimos formando nuestros hogares, nuestras familias y fuimos saliendo adelante de aquello tan cruel que nos dejó mal [Yeny Montes, habitante de El Pacífico. Entrevista, junio del 2016]. (Ruíz y Villa, 2017).

La sobrevivencia pasó a ser la lucha cotidiana de estos pobladores que la fueron resolviendo desde el acceso a la tierra por ocupación ilegal mayoritariamente, por procesos de autoconstrucción de vivienda mediante el convite o la forma comunitaria de satisfacer necesidades; la organización comunitaria, en especial la Junta de Acción Comunal, operó como estrategia sociopolítica para el acceso al agua, el alcantarillado, la electricidad y los equipamientos colectivos (como senderos, escalas, sedes comunales, escuela, entre otros). Sortearon, además, las condiciones de marginalidad y exclusión propias del territorio periférico y la estigmatización por extrema pobreza y violencia en estas zonas de ladera.

Según Gloria Naranjo (1992), en la década de 1960, algunos sectores de la población se vieron obligados a escalar la ladera oriental en busca de un techo donde vivir. Surgieron diversas invasiones en Medellín y fueron nombradas asentamientos informales, considerados algunos como barrios y otros como sectores, estos últimos en búsqueda de consolidación y reconocimiento como barrios para el acceso a inversiones públicas y la legalización de su vivienda. Situaciones que persistieron en la década de 1970 y 1980, aunque algunos de estos barrios luego se incluirían en procesos de rehabilitación por parte de entidades estatales.

Asimismo, para la década de 1970, se pusieron en marcha políticas de erradicación de asentamientos y reubicación de familias mediante la construcción de viviendas con aportes públicos y privados (Gómez, 2010, p. 49).

Por su parte, la institucionalidad dispuso para este periodo de planes de ordenamiento físico para organizar la ciudad desde su lógica. Por ejemplo, la expedición de la Ley 88 de 1947 del Plan Regulador, como la primera experiencia de planeación en Colombia, instrumento de gestión de la estructura urbana basado en preceptos del Congreso 
Interamericano de Arquitectura Moderna (CIAM) y alimentado por el espíritu de la Carta de Atenas (Del Castillo y Salazar Ferro, 2001, citados en Quinchía, 2013).Entre las directrices del plan están: zonificar la ciudad según actividades del hábitat, el ocio, el trabajo y la circulación; respetar el manejo y la ubicación de unidades residenciales y proyectar unidades vecinales; determina que el centro debía conservar oficinas, servicios institucionales y viviendas; concentrar la industria en el sur y separarla de las unidades residenciales por cordones verdes; los cerros debían ser reforestados y mantenerse como parques (Quinchía, 2013, p. 18).

De la misma manera, el Concejo de la ciudad aprobó para 1960 el Plan Director, donde se establece el sistema vial urbano primario y secundario. Luego, Planeación Municipal, creada como oficina para inicios de esta década con el fin de regular el funcionamiento y la expansión urbana, así como generar programas de rehabilitación, normalización y erradicación de núcleo de vivienda, precisó en 1968 el Plan Integral Municipal para atender necesidades de crecimiento de la ciudad y reglamento de urbanizaciones desde normas de zonificación y usos del suelo. También formuló el Plan Vial 1969-1971, donde se establecen los anillos centrales, así como la rectificación y la canalización del río y los alcantarillados.

El perímetro urbano, la forma de adquirir la tierra, la construcción de vivienda y el acceso a los servicios públicos domiciliarios en la ciudad son algunos de los asuntos que evidencian las contradicciones en las maneras de ordenar la ciudad. El perímetro urbano en Medellín se ha definido en tres ocasiones: en 1945 se establecieron las fronteras urbanas; en 1963 se incluyeron en este perímetro barrios del norte y occidente; y finalmente, en 1977, el Plan General de Desarrollo actualizó, reunió y unificó directrices sectoriales en el proceso urbano de la ciudad. Sumado a ello surgió en 1968 la Ley Nacional 166, conocida como ley antitugurios, que prohibía a los Gobiernos locales dotar de infraestructura física y servicios públicos a asentamientos piratas ubicados fuera del perímetro urbano (Quinchía, 2013, p. 26). Quizá estas restricciones estimularon la organización comunitaria, de cara a luchar por el reconocimiento de sus territorios, no como sectores, sino como barrios de la ciudad, lo cual 
posibilitaría procesos de legalización de tierras, acceso a la intervención pública en mejoramiento de vivienda, servicios públicos domiciliarios y equipamientos colectivos. En la medida que crecen en número los asentamientos informales en las laderas de la ciudad, con todo lo que implica asentarse en territorios desprovistos de condiciones materiales básicas para la sobrevivencia, se establece una dinámica de organización y participación comunitaria en procura del acceso a bienes colectivos que van garantizando procesos de apropiación territorial.

De esta manera, el acceso al servicio público domiciliario jugó un papel decisivo en el proceso de poblamiento de la zona de ladera. Mientras las comunidades autogestionan de manera solidaria el acceso a estos servicios mediante acciones colectivas de movilización y resistencia, hacen presión a las entidades encargadas para que instalen infraestructura pertinente. Para la década de 1960 se conformó como dependencia en las Empresas Públicas de Medellín (EPM) la División de Habilitación de Viviendas, que aplicó una política municipal denominada Fondo Rotatorio de Rehabilitación de Barrios y empezó a desarrollar procesos de regularización de vías y servicios públicos. EPM comenzó a dotar a algunos barrios con acueducto, alcantarillado y energía como criterio fundamental de rehabilitación, incluidos distintos asentamientos que presentaban carencias habitacionales y de integración con la ciudad, lo cual incentivó nuevas ocupaciones de terrenos con la expectativa de estos servicios (Velásquez, 2015, p. 49).

Estas reformas públicas, si bien dieron pie a la consolidación de los nuevos núcleos urbanos e indirectamente su incorporación a la ciudad formal, fueron también el resultado de la presión social y política de fuertes acciones colectivas y de movilización urbana promovidas desde los asentamientos y las organizaciones de los sectores populares de la ladera. Un problema que sin duda también marcó fuertemente el final de este periodo y los desafíos del venidero fue la crisis económica de los años 90 derivada de la recesión económica, agudizada sin duda por la apertura económica. Esto vino acompañado de una fuerte crisis social, política y cultural derivada de las dinámicas de violencia instauradas por el poderío del narcotráfico en la ciudad, que también entró como catalizador de la 
expansión urbana y puso en evidencia las condiciones de abandono y pauperización vividas en las zonas marginales de Medellín.

3. De campesino o citadino a ilegal (1990-2015). Para la década de 1990, por su parte, se inauguró en el país la Nueva Constitución Política, que propiciaba apertura democrática y económica, y retomó las estrategias para la descentralización política y administrativa del país ya iniciada años atrás con la elección popular de alcaldes. Esto trajo implicaciones importantes en los Gobiernos locales.

Este periodo se caracterizó por el aumento progresivo del poblamiento de la ciudad desde nuevos desplazamientos forzados que establecieron otras particularidades en la transformación de las dinámicas urbanas en tanto que "familias y grupos de campesinos desplazados por efectos del conflicto en zonas rurales, a los que se suma un importante número de desplazados intraurbanos, por efectos de la urbanización del conflicto y su expresión en confrontaciones interbarriales" (Naranjo, 1992, p. 336). La ciudad en su proceso de expansión urbana se ensanchó hacia las laderas, lo cual acentuó sus marcadas diferencias socioespaciales. Asimismo, Jaime Nieto (2008) reconoció que este fenómeno —el desplazamiento intraurbano - tuvo repercusiones fuertes en la configuración de nuevos barrios piratas en las laderas o las pendientes pertenecientes a la zona centro-occidental, de acuerdo con la agudización del conflicto armado en las zonas nororiental y centrooriental de la ciudad (pp. 120-121).

El incremento del costo de vida en la ciudad con los procesos de valorización del suelo urbano como efecto de la intervención urbana, en contraste con el detrimento de las condiciones de vida de los nuevos habitantes que evidenciaban el descenso social de su familia y la pérdida de poder adquisitivo aumentaron la presión al poblamiento de la ladera (Gómez, 2010). De un lado, se presionó con procesos de reubicación o el desalojo de moradores tradicionales o de barrios autoconstruidos bajo el discurso del riesgo de desastre natural; y, por otro, muchos de estos territorios fueron visualizados como espacios estratégicos para el desarrollo urbano de la ciudad, en respuesta al discurso imperante de su internacionalización como resultado de la apertura económica y la búsqueda de inserción en el nuevo ordenamiento económico mundial. 
Cambios muy importantes en la gestión urbana y la planeación del desarrollo de este periodo fueron los introducidos por la Reforma Urbana de 1989 y la Constitución Política de 1991, que brindaba mayor autonomía territorial y política frente a la orientación local del desarrollo urbano. Por esta vía, las intervenciones urbanas públicas en la ciudad se incrementaron para esta época y el control del perímetro urbano desde medidas concertadas y represivas, funcionales a los intereses de sectores privados que invertían en la valorización urbana, propició el acelerado e inequitativo crecimiento urbanístico desde la acumulación por despojo (Harvey, 2008). De la otrora Medellín con vocación industrial se transitó a la ciudad prestadora de servicios y de tercerización laboral, lo cual, en cuanto a la población que habita las laderas, repercutió considerablemente en su inserción en el mercado de fuerza de trabajo al disminuir la necesidad de obreros e incrementarse la demanda de empleados en el sector servicios, que requería mayor cualificación técnica.

Tanto la Medellín moderna y pujante (imaginada y proyectada desde su fundación), como las tendencias del capital global vieron como amenaza a los marginales pobladores urbanos de la ladera, en tanto se constituyeron en foco de desorden que afectaba el valor del suelo y complicaban las decisiones que requería la ciudad marketing (Borja y Castells, 1997). Desde su lógica y sus recursos, usurpaban territorios que podrían tener otro destino, habitaban lugares considerados de alto riesgo, pero además presionaban y reclamaban la presencia de la institucionalidad pública para la garantía y el acceso a los derechos fundamentales.

Pese a los esfuerzos por la contención y la erradicación de los asentamientos informales, la población de la otra ciudad, la de la carencia, la dificultad y la resistencia, era mayoría en la ciudad, así como lo era la informalidad en la manera de ordenar el espacio urbano, pues el 79,53 \% de la población de Medellín habitaba en sectores de estratos más bajos 1, 2 y 3, mientras que el 20,48 \% ocupaba barrios clasificados en estratos altos 4, 5 y 6 (Alcaldía de Medellín, 2014, p. 6).

Aunque el Municipio de Medellín, mediante Resolución 075 de 1992, adoptó la concepción de barrio subnormal que proviene del Documento 
Conpes 2326 de 1987, luego lo conceptualizó como informalidad urbana en el primer Plan de Ordenamiento Territorial, Ley 388 de 1997. Esta informalidad fue asumida de la siguiente manera:

Aquel espacio urbano que se caracteriza por el uso,ocupación y aprovechamiento de la tierra en forma no ordenada y no sujeto a la regulación de las autoridades encargadas de establecer el régimen del uso del suelo y la construcción de edificaciones. Es decir, es una forma de producción y reproducción de la ciudad, al margen o en contraposición al orden formal urbano. (DAP, 2015, citado en Velásquez, 2015, p. 26)

\section{FORMAS DE CONSTRUIR CIUDAD}

Una experiencia de intervención urbana importante para la época la constituyó el Programa Integral de Mejoramiento de Barrios Informales (Primed), que se inició en 1993 como programa del Gobierno local en alianza interinstitucional entre el Gobierno nacional y la Consejería Presidencial para la ciudad, la Alcaldía de Medellín y el Estado alemán con el banco KFW. Su objetivo fue aportar a la calidad de vida de los barrios subnormales de la ciudad por medio de mecanismos de planeación y gestión para el mejoramiento urbano mediante la promoción y la participación para la concertación de los proyectos. El mejoramiento barrial del Primed incluyó la infraestructura vial y los servicios públicos; las obras de estabilización y protección, adecuación de equipamientos educativos, de salud, de recreación; el mejoramiento de vivienda, y las acciones para la mitigación del riesgo geológico a través de obras de infraestructura y capacitación para el manejo y el control del medioambiente, además de la legalización de la tenencia de la tierra. Con el desmonte gradual del Primed a causa del cambio del Gobierno local, se priorizó en la ciudad la solución de vivienda masiva en altura con el Plan Parcial Pajarito, también conocido como la Ciudadela Nuevo Occidente en las afueras de Medellín, donde se reubican familias de diversos sectores como estrategia para contrarrestar la informalidad; política contraria a los efectos adversos en la convivencia y en la calidad de vida, en tanto se hicieron a un lado la diversidad sociocultural y las prácticas territoriales de los pobladores de los barrios autoconstruidos. 
El Plan de Ordenamiento Territorial de 1999 y los Planes de Regularización y Legalización Urbanística (PRLU) fueron definidos como instrumentos de planeación y gestión territorial en los asentamientos de desarrollo incompleto, donde las acciones de legalización y regularización urbanísticas estarían dirigidas a disminuir la ilegalidad en la tenencia derivada de la forma de urbanización y construcción de las edificaciones. El punto de quiebre de estos planes fue en el 2004, cuando se plantearon las intervenciones en asentamientos informales, orientadas desde los Proyectos Urbanos Integrales (PUI) para 12 años, los cuales propiciaban el surgimiento del discurso del urbanismo social, que posteriormente obtuvo importantes reconocimientos internacionales (Velásquez, 2015, p. 57).

Los PUI se estructuraron desde tres componentes: fisico, social e institucional. Las intervenciones físicas buscaban crear ambientes seguros frente a los riesgos ambientales, sociales y urbanos, que incluían acciones de construcción y mejoramiento del espacio público, movilidad, equipamientos públicos y recuperación del medioambiente. En el componente social, se promovió la participación comunitaria a fin de avanzar en la concertación y la solución de las problemáticas sentidas por la población. En el institucional, se fundamentó el concepto de integralidad, que implicaba, entre otros, el conocimiento del territorio, el manejo responsable del dinero, y la planeación y gestión del proyecto (Puerta, citado en Velásquez, 2015). No obstante, esta iniciativa de Gobierno no tuvo continuidad en la alcaldía siguiente de Aníbal Gaviria, quien volcó la atención en la construcción de megaproyectos urbanos en los territorios de los barrios informales, orientados a dar nuevas puntadas al proyecto de internacionalización de la ciudad.

En esta dirección, otra de las estrategias diseñadas desde la institucionalidad para ordenar el espacio urbano ha sido el Cinturón Verde Metropolitano (CMV), pensado para la ciudad desde la década de 1970 como barrera natural para controlar la expansión urbana. Esta idea se retomó como CMV y en el 2013, bajo el discurso del urbanismo cívico-pedagógico, pasó a denominarse Jardín Circunvalar de Medellín, cuya construcción fue delegada a la Empresa de Desarrollo Urbano (EDU) para realizar los diagnósticos, los planes maestros y las intervenciones asociadas a la movilidad con el camino de la vida, el sendero de bicicletas y el monorriel, como estrategia 
de intervención en los asentamientos informales de la zona centro-oriental, básicamente dirigida a la generación de espacio público bajo el discurso de la sostenibilidad ambiental y la contención de la expansión urbana (Velásquez, 2015, p. 65).

Por su parte, en el nuevo POT de la ciudad (Acuerdo 48 de 2014), se asumieron estos asentamientos informales como zonas de desarrollo incompleto e inadecuado y se planteó el tratamiento de mejoramiento integral en el artículo 243:

Este tratamiento corresponde a las zonas homogéneas identificadas como "Áreas de Desarrollo Incompleto e Inadecuado", donde se localizan los asentamientos humanos en situación de marginalidad y segregación socioespacial, en los cuales se concentra población en situación crítica de pobreza, al margen de las oportunidades del desarrollo, con limitaciones de acceso a los bienes y servicios públicos esenciales como la educación y la salud, dando lugar a las bajas condiciones de vida de los habitantes (POT de Medellín, 2014).

Ahora bien, en clara situación de disputa con la institucionalidad y su normativa sobre el ordenamiento del territorio, han emergido, desde los territorios de ladera, propuestas de Mejoramiento Integral de Barrios ${ }^{3}$ (MIB) por parte de organizaciones sociales, para incidir en las políticas locales de vivienda y ordenamiento territorial. Se soporta en los múltiples problemas de vivienda y de hábitat en los barrios de ladera, sumados a la intervención de los megaproyectos de transformación urbana. Por ello, en este proceso de movilización social se plantea la urgencia de repensar los procesos de planeación y gestión territorial urbana de los barrios autoconstruidos, incluido un enfoque comunitario que permita comprender las propuestas desde la historicidad de los pobladores que interpelen el modelo de ciudad

3 El Mejoramiento Integral de Barrios, si bien surge como la consigna de movilización social desde estos ejercicios de participación comunitaria, tiene también su antecedente en las políticas gubernamentales internacionales y nacionales. El MIB es una estrategia de gestión territorial que nace en el contexto del encuentro de UN-Habitat de 1999 con el lema de ciudades sin tugurios. Para el caso de Colombia, este modelo fue adoptado por el Estado a través del documento Conpes 3604 de 2009. Política que, si bien guarda similitud con las propuestas comunitarias, es ampliada en su concepción de participación ascendente y la inclusión de aspectos sociales, culturales y económicos que superen la visión físico-biótica del territorio. 
impuesto y construyan un correlato con las políticas y acciones del gobierno local (Mesa de Vivienda y Servicios Públicos, comuna 8, 2016).

Dicha estrategia se deriva y legitima a partir de procesos amplios de participación comunitaria, como la consulta popular, como vía para concertar con las comunidades los tres ámbitos que la componen:1) vivienda,2) entorno y hábitat popular, y 3) condiciones de seguridad alimentaria y económica, cuyo propósito es crear garantías de permanencia de los habitantes en estos territorio en condiciones dignas. Desde un enfoque territorial diferencial y de reivindicación de derechos, el MIB pretende aportar al debate sociopolítico en la ciudad, desde la deliberación y la confrontación entre la comunidad organizada y el gobierno local, de cara a establecer lineamientos que coincidan con las reales necesidades de las zonas de ladera, para la formulación de políticas públicas urbanas que estén incluidas, así como para evidenciar la necesidad de conjuntar esfuerzos y dirimir las disputas sobre los destinos del territorio en el marco de la renegociación del modelo de ciudad.

\section{CONCLUSIONES}

En las formas de producir y reproducir la ciudad de Medellín desde el acceso a la tierra y a la construcción de vivienda, así como en las definiciones del perímetro urbano y la disposición del suelo urbano, se pueden indicar las tensiones entre la ciudad imaginada y la real. La primera es la planeada y proyectada desde la formalidad y la oficialidad, mientras que la ciudad real es la que habitan los nuevos moradores en su lucha por la sobrevivencia, la que hacen en procesos de ocupación de tierras en la zona de ladera, la que construyen desde sus viviendas y maneras de significar los territorios.

Las intervenciones en los territorios, los sentidos y horizontes de estar y ser en la ciudad son lógicas y racionalidades diversas, según los actores implicados. Mientras la primera se orienta a la planeación física y a la legislación del deber ser de Medellín, la segunda enfrenta en el día a día la presión de sobrevivir en la disputa por un lugar para hacer vivienda mediante autoconstrucción, acceder a servicios públicos como agua y electricidad y dotarse de equipamientos colectivos mediante la gestión comunitaria. Es la tensión entre la ciudad que se planea en conexión con el mundo y las exigencias del mercado global, y 
la que se visualiza y construye como posibilidad para rehacer las condiciones materiales e inmateriales que favorezcan la reproducción de la vida frente al fenómeno del desplazamiento forzado por la violencia social y política del país. Dos construcciones de ciudad que se saben antagónicas, en disputa permanente y, por tanto, ponen en tela de juicio las maneras en que, desde la institucionalidad, se da tratamiento a la política urbana; más allá de esto, interrogan la visión de ciudad instituida por las élites económicas y políticas.

La expresión en el tiempo de estas dos lógicas se puede evidenciar en los tránsitos del campesino en el espacio urbano, según motivos de movilidad a la ciudad, formas de acceder a la tierra y la vivienda, así como la lucha permanente por generar condiciones de vida de la población de la ladera o zonas marginales de la ciudad: del campesino al obrero entre las décadas de 1920 y 1940, cuando la ciudad era parte de la promesa del desarrollo industrial como fuente de empleo y ascenso social a categoría de obrero; y se dio el vínculo con la fábrica como la posibilidad de satisfacer necesidades familiares y proyectar la formación de descendencia; de campesinos a desarraigados entre 1945 y 1990, como un periodo de desplazamiento forzado del campo a la ciudad por la violencia entre partidos políticos inicialmente y luego por grupos armados, donde la organización comunitaria desde Convites y Juntas de Acción Comunal eran estrategias para satisfacer necesidades colectivas y avanzar en disputa por el reconocimiento del derecho a la ciudad.

Entre 1990 y 2015, se presentó una transición de campesinos o citadinos a ilegales, ante los nuevos desplazamientos intraurbanos tanto por la violencia como por las intervenciones urbanas, que sobrevaloraron los costos de habitar los territorios y que originó el desplazamiento de los moradores. Los nuevos pobladores que se han asentado en la ladera de la ciudad buscan dónde poner su cuerpo mediante procesos de ocupación de terrenos y autoconstrucción de sus viviendas desde la gestión comunitaria. La presión por ser reconocidos como parte de la ciudad e incorporados a la lógica de la planeación urbana para acceder a recursos públicos es vital para estos moradores que, además de enfrentarse a la arremetida de la fuerza pública ante los intentos de desalojo y a los actores armados del territorio que pretenden regular su convivencia, también deben sortear las vicisitudes socioeconómicas y luchar cotidianamente para acceder a recursos que permitan la supervivencia de la 
familia en la ciudad, así como afrontar las inclemencias de la naturaleza al ubicarse en zonas de pendientes. Son estas distintas formas de hacer ciudad las que reclaman ser visibilizadas y nombradas desde sus habitantes reales; las maneras de construir Medellín desde los nuevos moradores que luchan cotidianamente por ser reconocidos en una ciudad que incrementa la brecha social debido a la concentración de la riqueza y la segregación socioespacial.

\section{REFERENCIAS}

Alcaldía de Medellín. (2014). Informe de calidad de vida. Recuperado de http://www.medellincomovamos.org/download/presentacion-informede-calidad-de-vida-de-medellin-2014-2015-2

Borja, J., y Castells, M. (1997). Local y global. La gestión de las ciudades en la era de la información. Barcelona:Taurus.

Carballeda, A. (2012). Política social, multiculturalismo e intervención en lo social. Debate público. Reflexión de Trabajo Social, 4(2). Recuperado de http://trabajosocial.sociales.uba.ar/wp-content/uploads/ sites/13/2016/03/06_Carballeda.pdf

Consejo Nacional de Política Social. (2009). Lineamientos para la consolidación de la Política de Mejoramiento Integral de Barrios MIB. Bogotá: Departamento Nacional de Planeación. Recuperado de http:// www.minvivienda.gov.co/Mejoramiento\%20Integral\%20de\%20Barrios/ Lineamientos\%20para\%20la\%20Consolidaci\%C3\%B3n\%20de \%20la $\% 20$ Pol\%C3\%ADtica\%20de\%20MIB.pdf

Giraldo, J. (2015). Aportes sobre el origen del conflicto armado en Colombia, su persistencia y sus impactos. En Comisión Nacional de Memoria Histórica y víctimas. Contribuciones al entendimiento del conflicto armado en Colombia. Recuperado de http://www.altocomisionadoparalapaz.gov. $\mathrm{co} / \mathrm{mesadeconversaciones/PDF/Informe} \% 20$ Comisi_n\%20Hist_rica\%20 del $\% 20$ Conflicto $\% 20 y \% 20$ sus $\% 20$ V_ctimas. $\% 20 \mathrm{La} \% 20$ Habana $\% 2 \mathrm{C} \% 20$ Febrero\%20de\%202015.pdf 
Gómez, E., Vázquez, G., Pérez, N., Tamayo, M., Gómez, C., Osorno, N., Gómez, G. Suárez, C., Valencia, S., y Atehortúa, O. (2010). Vivir bien frente el desarrollo. Procesos de planeación participativa en Medellín. Medellín: Pregón.

Gómez, G. (2010). Desplazamiento forzado y periferias urbanas: La lucha por el derecho a la vida en Medellín (tesis doctoral). Escola Nacional De Saúde Pública Sergio Arouca ESNP. Rio de Janeiro, Brasil.

González, L. (2007). Medellín, los orígenes y la transición a la modernidad: crecimiento y modelos urbanos 1775-1932. Recuperado de http://www. bdigital.unal.edu.co/2226/1/Luis_Fernando_Gonzalez.pdf

Harvey, D. (2008). El derecho a la ciudad. NLR, 53, 23-39.

Melo, J. (1997). Espacio e historia en Medellín. Recuperado de http://www. jorgeorlandomelo.com/espaciomedellin.htm

Mesa de Vivienda y Servicios Públicos, Comuna 8. (2016). Lineamientos comunitarios para una política de mejoramiento integral de barrios (DT) Manuscrito inédito. Medellín.

Municipio de Medellín. (2014). Plan de Ordenamiento Territorial del Medellín. Acuerdo Municipal 048 de 2014. Por el cual se revisa y ajusta el Plan de Ordenamiento Territorial para el Municipio de Medellín y se dictan otras disposiciones. Recuperado de https://www.medellin.gov.co/irj/go/ km/docs/pccdesign/SubportaldelCiudadano_2/PlandeDesarrollo_0_17/ ProgramasyProyectos/Shared\%20Content/Documentos/2014/POT/ ACUERDO\%20POT-19-12-2014.pdf

Naranjo, G. (1992): Medellín en zonas. Monografias. Medellín: Corporación Región.

Nieto, J. (2008). Resistencia civil no armada al conflicto armado y la exclusión social. Casos comunas 8, 9 y 13 de Medellín: 2002-2006, (Informe final de investigación). Medellín: Universidad de Antioquia, Comité de Desarrollo de Investigación. 
Perfetti,V. (1996). Tres proyectos para un deseo: una ilusión de una ciudad. En Jorge Orlando Melo (Ed.), Historia de Medellín (t. I). Bogotá: Compañía Suramericana de Seguros.

Primed. (1996). Primed. Una experiencia exitosa de intervención urbana. Recuperado de http://unesdoc.unesco.org/images/0012/001297/1297 76so.pdf

Programa de las Naciones Unidas para el Desarrollo. (2011). Colombia rural, razones para la esperanza. Informe ejecutivo. Bogotá: PNUD.

Quinchía, S. (2013). Discurso oficial, representaciones sociales y prácticas espaciales: Un acercamiento al urbanismo social en Medellín (Informe final de investigación). Medellín: Institución Universitaria Colegio Mayor de Antioquia, Grupo de Investigación Estudios en Desarrollo Local y Gestión Territorial.

Romero, J. (1976). Latinoamérica, las ciudades y las ideas. Buenos Aires: Siglo XXI.

Ruíz, L., y Villa,H. (2017). Proceso de poblamiento barrio El Pacífico (Informe de investigación). Manuscrito inédito. Medellín: Institución Universitaria Colegio Mayor de Antioquia / Junta de Acción Comunal El Pacífico / Mesa de Vivienda y Servicios Públicos de la Comuna 8.

Velásquez, C. (2015). Transformaciones del Estado local y sus prácticas de intervención en sectores informales de Medellín, a partir de la experiencia de Mejoramiento Integral de Barrios (1990-2015) (tesis de maestría). Universidad Nacional de Colombia, Medellín, Colombia. 
